\title{
Studies upon an Oral Aerobic Actinomycete
}

\author{
By G. H. G. DAVIS AND J. H. FREER \\ Department of Bacteriology, University of Birmingham
}

(Received 27 February 1960)

\begin{abstract}
SUMMARY
An aerobic actinomycete isolated regularly from the human mouth is described. This organism possesses the cultural, morphological and biochemical characters of Ørskov's Group $2 \mathrm{~b}$, or more specifically, the genus Nocardia. Although the results of cell-wall analyses differ from those obtained in this and previous studies upon other species of Nocardia, we nevertheless feel that provisional classification in the genus Nocardia is valid upon the present evidence. The specific name $N$. salivae is proposed.
\end{abstract}

\section{INTRODUCTION}

Gram-positive bacteria which exhibit morphological features of the order Actinomycetales occur commonly and regularly in the human mouth (Bisset \& Davis, 1959). Morphological criteria are of prime importance in the subdivision of this order into families and genera, although many attempts have been made to supplement this approach with biochemical, serological and other information, with varying degrees of success. The main point which emerges from any close examination of this large group of bacteria is that here, as in many other groups, the lines of demarcation between genera are not clear. For instance, if one examines typical strains of Streptomyces, Actinomyces, Nocardia, and Mycobacterium, it appears obvious that Streptomyces is characterized by its permanent mycelium, aerial hyphae and chains of spores, Actinomyces by its anaerobic tendencies, Nocardia by its fragmenting impermanent mycelium, and Mycobacterium by its small size and acidfastness, among other characters. In nature, however, there commonly occur strains of all these genera which not only fail to exhibit the more obvious characteristics of the genus to which they are assigned, but which appear to possess characteristics of other genera. Examples of this are: mycobacteria which produce mycelium and are not acid-fast; nocardias which form aerial mycelium and spores, or which simulate mycobacteria; actinomyces which grow aerobically, with rudimentary aerial hyphae; streptomyces without aerial hyphae or spores. The various morphological appearances which the Actinomycetales produce can in fact be almost as great a taxonomic hazard as they appear to be a blessing. For example, Jensen (1932) pointed out that the sporophores of Micromonospora closely resemble similar structures in 'Actinomyces' (i.e. Streptomyces) and 'Proactinomyces' (i.e. Nocardia); Bisset (1957) also compared these structures with similar ones in Actinomyces odontolyticus, a microaerophilic parasite, and discussed the probable significance of these similarities. In addition to this type of apparent cross-relationship between relatively well-established genera of the order Actinomycetales, the taxonomy of the group is further complicated by the occurrence of a number of 
organisms which possess certain of the group characteristics but which are not currently generally accepted as members of the group, such as Lactobacillus bifidus, Propionibacterium, Corynebacterium, Arthrobacter, Leptotrichia, etc. (see Bergey's Manual, 1957).

Of the genera which are accepted as members of the Actinomycetales, Nocardia is one of the largest and most poorly classified. Members of this genus occur most commonly in soils, but various pathological conditions in man and other animals have been associated with certain species. Considerable variation in morphological and biochemical potential is characteristic of the genus Nocardia as it is currently defined.

In 1954 Morris pointed out that many of the so-called Actinomyces of the human oral flora were more accurately classified as Nocardia; he described a number of types but was unable to identify them with any known species, most of which are relatively poorly defined. The dental literature abounds with references to 'actinomyces' and 'actinomyces-like bacteria' (Rosebury, 1944), particularly in relation to the problem of dental calculus formation, e.g. Naeslund (1926). Most of these reports are difficult to evaluate taxonomically because inadequate descriptions were made. An idea of the associations between actinomycetes and oral conditions can be gathered from the list given by Dodge (1936); some of the oral types (all called 'Actinomyces') described in that work are clearly very streptomyces-like, e.g. ' $A$. buccalis', and others may be assumed, but not proved, to be nocardias, e.g. 'A. Rodellae'.

In many references to oral and other organisms of the Actinomyces-Nocardia type the problem of generic allocation has been circumvented by resorting to the designation used by Ørskov (1923) as 'members of Group $2 b$ '. Ørskov's Group $2 b$ included those nocardias which do not simulate Streptomyces and also the microaerophilic types now called Actinomyces. This grouping reflects the way in which the two genera Nocardia and Actinomyces tend to merge together, especially in morphological characters. But this is not the only direction in which Nocardia appears to merge into another genus; it does so with both Mycobacterium and Streptomyces. It is interesting, and somewhat disconcerting, to note that Actinomyces, Streptomyces and Mycobacterium are not only currently classified as separate genera, but also in separate families, and yet with all three Nocardia shows certain affinities, or appears to do so. Various possible explanations for this situation are available, the most likely being either that Nocardia, in its various forms, represents facets of the primitive, basic actinomycete from which the other forms have evolved, or that Nocardia represents a collection of semi-degenerate streptomyces, micromonosporas, actinomyces, etc. Considering the apparent specialization exhibited by most other genera of the order Actinomycetales it seems that the former hypothesis is more appropriate. The present work does not set out to prove or disprove this hypothesis, but only to provide taxonomically useful information.

Some information on the organism described here has already been published (Davis \& Baird-Parker, 1959b). 


\section{RESULTS}

\section{Isolation and Culture of Nocardia salivae}

Isolates of the organisms to be described and which it is proposed to name Nocardia salivae were first obtained during the process of isolating Leptotrichia dentium (Baird-Parker \& Davis, 1958; Davis \& Baird-Parker, 1959). Submerged cultures of saliva and materia-alba were made in NAYS agar (composition: nutrient broth containing $\mathbf{0 . 3} \%(\mathrm{w} / \mathrm{v})$ yeast extract, $0.2 \%(\mathrm{w} / \mathrm{v})$ soluble starch and $1 \%$ $(\mathrm{w} / \mathrm{v})$ agar, $\mathrm{pH} \mathbf{7 \cdot 0})$. After incubation for 2-3 days at $37^{\circ}$ colonies were selected (see section on Morphology) with the aid of a low-power dissecting microscope, and subcultured in further pour plates and on the surface of NAYS agar. With a little experience it was easy to distinguish between colonies of the nocardia-like organism here described and those of Leptotrichia dentium, the latter being like balls of hair in submerged culture and giving smooth, heaped-up colonies with irregular (lobate) and noticeably filamentous margins in surface culture. The grossly filamentous nature of $\boldsymbol{L}$. dentium is in fact characteristic, whereas the nocardia-like organism has never shown this feature in its colonies. Subsequently most isolates were obtained from aerobic surface cultures upon NAYS agar or blood agar. Strains of N. salivae were obtained from almost all the mouths examined.

Growth of Nocardia salivae in nutrient broth sometimes failed or was very slow but was usually fairly good and produced a smooth turbidity with small floccules. In semi-solid nutrient agar $(0.3 \%, \mathrm{w} / \mathrm{v}$, agar $)$ the nocardias produced smooth confluent growth on the surface. Growth upon nutrient agar was often adequate in $24 \mathrm{hr}$., and this faster growth rate served to distinguish further between strains of $N$. salivae and those of the slower growing Leptotrichia dentium. Strains of $N$. salivae did not grow under strictly anaerobic conditions but were satisfactory in air and air $+10 \%(\mathrm{v} / \mathrm{v}) \mathrm{CO}_{2}$. Good growth was obtained upon inspissated serum, LowensteinJensen medium, liver extract agar, Dorset's egg medium (with and without glycerol), $5 \%$ horse blood agar, potato-nutrient agar (Waksman, 1950), and at and near the surface of Brewer's medium. Poor growth occurred on oatmeal agar (Waksman, 1950), and no growth on glucose-asparagine agar, or in gelatin stab cultures. When growth occurred its character was basically similar on all media. Of the chemically defined media tested only that of Gray \& Thornton (1928) supported some growth; addition of glycerol or glucose $(1 \%)$ or a drop of liquid paraffin/tube (see Umbreit, 1939) improved growth.

It was noticed that Nocardia salivae grew more readily upon solid than liquid media and an effort was therefore made to evolve a satisfactory liquid medium. It was found that nitrate stimulated growth and by mixing the salt solution of Czapek-Dox with nutrient broth a very satisfactory medium was obtained. This mixture was later modified to the following (g./100 ml. water): Lab Lemco, 0.5; peptone (Oxoid), 0.5; $\mathrm{FeSO}_{4}, 0.001 ; \mathrm{NaCl}, 0.05 ; \mathrm{MgSO}_{4} 7_{\mathrm{H}} \mathrm{O}, 0.05 ; \mathrm{K}_{2} \mathrm{HPO}_{4}, 0.1$; $\mathrm{KNO}_{3}, 0 \cdot 1$; adjusted to $\mathrm{pH} 7 \cdot 0$. This medium will be called Lemco salts medium (see section on Biochemical characters).

During growth of Nocardia salivae in Lemco salts medium the $\mathrm{pH}$ value rose to c. 8.0 in $24 \mathrm{hr}$., but when glucose or sucrose was present this initial $\mathrm{pH}$ increase was followed by a decrease to $c$. pH $5 \cdot 2$ (2\% glucose) in 3 days. Whether the initial pH increase was due to ammonia production from nitrite or from some protein 
constituent was not ascertained. Traces of ammonia were detected in nitrite reduction tests using Nessler's reagent, but none was detected in tests with arginine hydrochloride as potential source of ammonia. Growth in broth cultures was often adherent to the tube walls and this character was significantly increased in broths containing fermentable carbon sources. It was also noted in test broths adjusted to $\mathrm{pH} \mathrm{5.5}$ with hydrochloric acid in the absence of carbohydrate, and is probably related to growth at low $\mathrm{pH}$ values. Recent tests with a solid version of Lemco salts medium indicate that it may prove useful as a semi-selective primary isolation medium for oral nocardias; this aspect will be studied further.

\section{Morphology of Nocardia salivae}

Colonial form. Submerged colonies in NAYS agar are small, discrete, very dense and irregular in outline, resembling a grain of sand or soil crumb.

Surface colonies (see Pl. 2) on NAYS agar vary considerably in appearance. They commonly commence as small, granular, entire, slightly raised colonies which often develop a dark central spot (seen when viewed by transmitted light). Older growth is relatively flat, dry and wrinkled, often curling away from the substrate at the margins to produce a lily-leaf like appearance (Pl. 2, fig. 14). In some cases growth is relatively smooth, soft and entire (Pl. 2, fig. 7), and in others extremely rough, irregular, hard and sunk into the substrate (Pl. 2, fig. 15). Intermediate granular, segmenting colonies commonly occur (Pl. 2, figs. 10, 11 and 13). These various colonial forms appear to be related to the type of cell forms in them, the smooth and granular forms being largely composed of coccoid and short forms and the heaped-up, adherent rough types of more filamentous cells.

On primary isolation plates colonies may appear to be erupting from the agar as rosettes (see Pl. 2, fig. 15), or lying almost free upon the surface as rough granules.

Adherence to the substrate is common, and usually results in colonies with crimped edges, somewhat resembling the primary growth of Streptomyces. These colonies are, however, seldom as large or as solid in consistency as those of Streptomyces, being usually composed of a mealy or crumbly top and adherent base. In many cases complete colonies can be removed from the agar without breaking up; in others the colonies fragment in a brittle fashion when disturbed. Colonies are invariably creamy white in colour; no sign of aerial mycelium formation was detected. We should like to draw attention to the similarities between the colonial forms of Nocardia salivae and those recently described by Howell, Murphy, Paul \& Stephan (1959) in oral Actinomyces spp.

Cellular form. Nocardia salivae exhibits a wide range of cell forms and arrangements of the type normally associated with members of the genus Nocardia. It is always Gram-positive and motility has not been observed. The cells are robust and vary considerably in diameter.

In Fig. 1 the range of cell forms is indicated by drawings; the sequence from $A$ to $\mathrm{W}$ is not intended as a cycle of development; the arrangement merely shows the simpler forms first and more complex last. In some cases, however, it does seem likely that adjacent forms represent parts of a development cycle, e.g. A produces $B ; S$ produces $T$ which fragments to form $U$, etc. One of the striking features of the simpler cell forms illustrated in Fig. 1, notably A, B, D, E, F, G, K, V, is their similarity to the cell forms described for Arthrobacter spp. (Conn \& Dimmick, 1947). 
The 'cystites' and 'tripodal cystites' of Chaplin (1957) are clearly simulated in drawings $A, G, K$ and $V$, as also are the 'opposite' and 'adjacent angles' of Sundmann (1958) in drawings $\mathrm{F}$ and $\mathrm{D}$ (see also Pl. 1, figs. 2, 4). It is interesting to note here that in the newly introduced comprehensive key in Bergey's Manual (1957), Skerman points out (p. 1009) the very close similarity between Arthrobacter and Nocardia. Attention is also drawn to the similarity between the reported 'gonidia' formation in Arthrobacter (Chaplin, 1957) and the frequent reports of

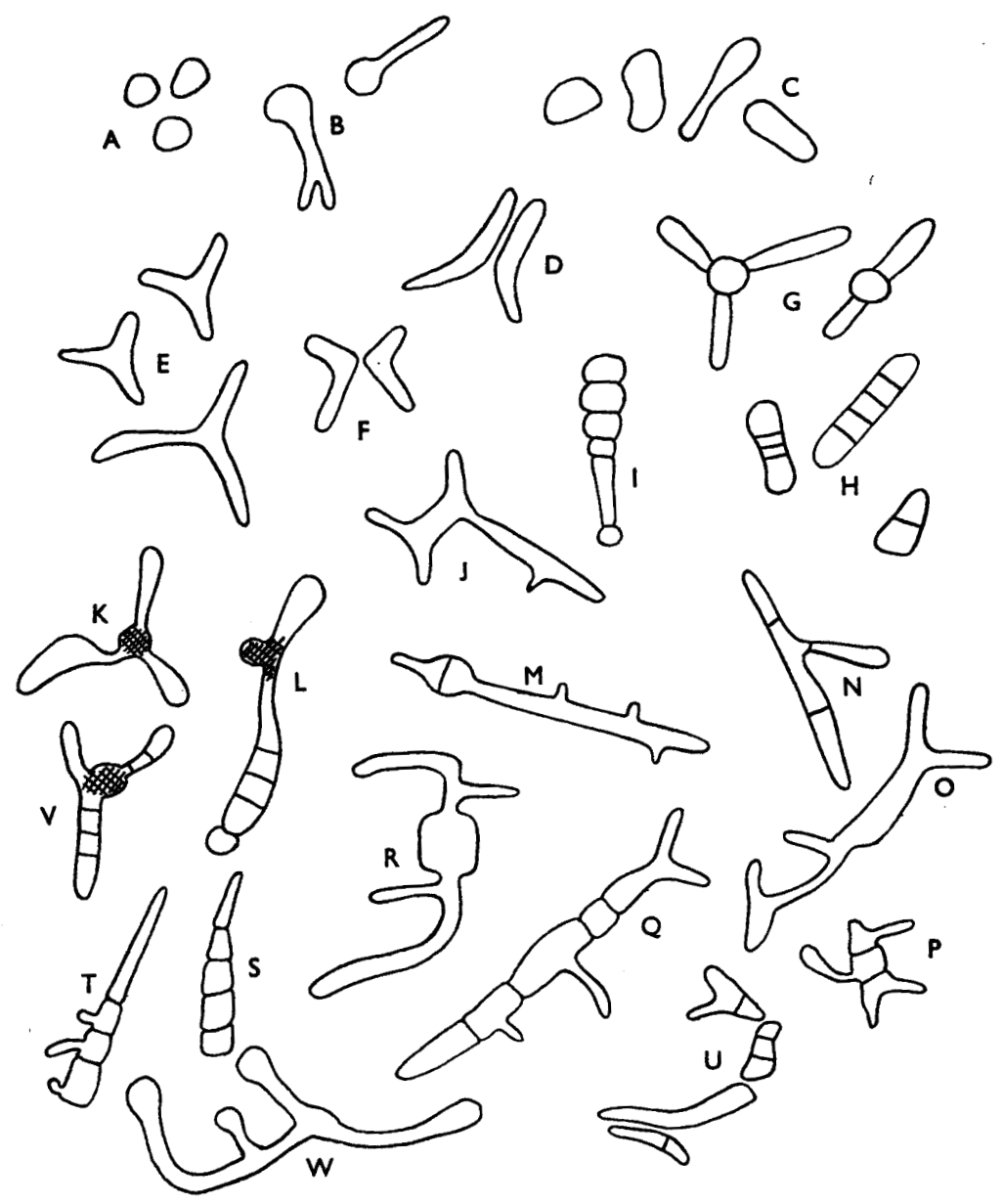

Fig. 1. Drawings of representative cell forms exhibited by the oral aerobic actinomycetes (Nocardia salivae) of this study, observed in preparations stained to show cell walls. Crosshatching $(K, L, V)$ indicates occurrence of densely staining areas.

apparently similar processes in Nocardia (Bergey's Manual, 1957, p. 715), Leptotrichia (Bulleid, 1924), and Streptomyces (Dreschler, 1919); such forms were not common in the present organism, but in $\mathrm{Pl}$. 2, fig. 9, an appearance which is grossly similar is shown, i.e. apparent coalescing of the cytoplasm within the cell wall. Similarities between certain cell forms in Fig. 1 and those reported by 
Morris (1951) as stages in the life cycle of Actinomyces bovis (see Morris's fig. 1, stages 1-7, 11-23) are noticeable, as also are those between the figs. 5 and 20,21 of Webb, Clark \& Chance (1954) and Fig. $1 \mathrm{D}$ and $\mathrm{H}$, respectively, of the present work.

Filament formation is common (Pls. 1 and 2, figs. 1, 5, 8, 9 and 12), as is branching (Pl. 1, figs. 1, 5) and segmentation followed by the production of buds (Pl. 1, fig. 3); although budding preceding septation (Pl. 1, fig. 6) and leading to branching (Pl. 1, fig. 1) also occurs. Terminal swelling of filaments (Pl. 2, figs. 8, 9 and 12) and swollen short forms (PI. 1, fig. 4) are common. The triradiate (see 'tripodal cystites' above) and short-paired angle forms (see also above) characterize this organism when growing in the short mycelial form. Although long branching filamentous forms are produced, mycelium formation is only rudimentary and not comparable with that which occurs in Streptomyces or Nocardia asteroides (see Bisset, 1955, p. 96). Preliminary attempts to follow the morphological development cycle of these bacteria were unsuccessful. The cells appear capable of reproducing indefinitely in certain forms, e.g. coccoids, over periods of days. It is, however, clear that many of the cell forms interpreted by previous workers as stages of lifecycles in Nocardia and Actinomyces can be observed in this bacterium. It is our opinion that the morphological potential of members of the order Actinomycetales constitutes a wide and, to a large extent, overlapping series of cell forms, and that the present organism exhibits many of those which place it taxonomically in the centre of the Nocardia range.

\section{Biochemical characters of Nocardia salivae}

Two series of tests were conducted, with an interval of six months between. In the first series 10 strains were used and in the second 20 , five of which were strains from the first series. Some of the strains used were relatively fresh isolates while others had been in cultivation for one and a half to two years; no differences were noticed between fresh and old isolates, or in the results they gave. Owing to the poor growth obtained in liquid cultures in the earlier stages of this study (see section on Culture), the first series of tests were made on solid media whenever possible, e.g. fermentation tests in stab cultures, though nitrate and nitrite reduction, hippurate and aesculin hydrolysis and glucose utilization, etc., were tested in liquid media. The basal medium ( $\mathrm{pH} \mathrm{7 \cdot 0)}$ consisted of nutrient broth $+0.3 \%(\mathrm{w} / \mathrm{v})$ yeast extract. In the second series of tests Lemco salts broth (see section on Culture) was used as the basal medium, and most tests, including fermentations, were made in liquid medium.

The two series reported were not exact duplicates in respect of tests carried out, technique of testing or results, and discrepancies are noted in the relevant tests by referring to the first series as $\boldsymbol{A}$ and the second as $B$. The fractional figures indicate strains positive/strains tested.

Catalase. On NAYS agar $(A$ and $B)$ positive: on Lemco salts agar $(B)$ positive.

Nitrate reduction. $0.05 \%(\mathrm{w} / \mathrm{v})$ potassium nitrate and $0.1 \%(\mathrm{w} / \mathrm{v})$ agar added to broth, 7 days: $A$ 9/10 positive; $B$ positive.

Nitrite reduction. $0.01 \%(\mathrm{w} / \mathrm{v})$ potassium nitrite and $0.1 \%(\mathrm{w} / \mathrm{v})$ agar added to broth, 7 days: $A 9 / 10$ positive; $B$ (with Lemco salt base without $\mathrm{KNO}_{3}$ ) $18 / 20$ positive.

Hydrogen sulphide production. $A \mathbf{0 . 0 5} \%(\mathrm{w} / \mathrm{v})$ L-cysteine hydrochloride in agar slopes, lead acetate paper, 7 days: $A$ and $B$ negative. 
Hippurate hydrolysis. $1 \%(\mathrm{w} / \mathrm{v})$ sodium hippurate in liquid medium, tested with $50 \%$ sulphuric acid, 7 days: $A$ 2/10 positive, $B$ negative.

Aesculin hydrolysis. $0.5(\mathrm{w} / \mathrm{v})$ aesculin and $0.05 \%(\mathrm{w} / \mathrm{v})$ ferric ammonium citrate: $A$ and $B$ positive 1-3 days.

Arbutin hydrolysis. $B$ only, tested as with aesculin: positive but slower than aesculin, $c .5$ days.

Glycerol utilization. $\boldsymbol{A}$ and $\boldsymbol{B}$ using stab cultures $+\mathrm{pH}$ indicator (Bromocresol purple) and $1 \%(\mathrm{v} / \mathrm{v})$ glycerol: acid production readily apparent at agar surface only; when sealed with liquid paraffin ( $B$ only) no acid production. Tests in liquid medium $(B)$ gave very slow positive results, i.e. 15-25 days, but heavy growth. (See section on Culture).

Final pH value in $2 \%(w / v)$ glucose broth. $A$ and $B, \mathrm{pH}$ tested over 7-day period, from second day onward pH was $5 \cdot 2 ; A$ only with $1 \%(\mathrm{w} / \mathrm{v})$ glucose $\mathrm{pH}$ 5.8-6.0.

Acetylmethylcarbinol production. $A$, with $1 \%(w / v)$ glucose, $1 / 10$ positive: $B$, with $2 \%(w / v)$ glucose, $19 / 20$ positive. Tested by Barritt's method (note probable effect of increased glucose concentration in $B$ ).

Litmus milk. $B$ only, no reaction in 10 days.

Gelatin liquefaction. Method of Smith (1946): $A$ and $B$, positive.

Starch hydrolysis. Starch $0 \cdot 2 \%(\mathrm{w} / \mathrm{v})$ in agar plate method: no or extremely slight hydrolysis.

Growth in chemically defined liquid media. Czapek-Dox negative or very slight; Dulaney (1948) medium B, negative; Gray \& Thornton (1928), usually weakly positive. See section on Culture for other media.

Carbohydrate fermentations. Concentrations $1 \%(\mathrm{w} / \mathrm{v})$, observed over 21 days: glucose, maltose, fructose, sucrose, trehalose, glycerol and arbutin ( $A$ only) fermented by all strains in $A$ and $B$. Mannose fermented by $2 / 10$ strains in $A$, by all strains in $B$. Galactose, lactose, arabinose, xylose, rhamnose, melibiose, melezitose, raffinose, dextrin, inulin, glycogen, starch, dulcitol, erythritose, mannitol, sorbitol, inositol, cellobiose, salicin not fermented. No gas was produced from any sugar ( $B$ only). Indicator changes in series $A$, i.e. stab cultures, occurred only at and near the surface of the medium and suggest oxidative rather than fermentative dissimilation of carbohydrates.

Acid-fastness. Organisms from NAYS agar were resistant to $1 \%$ sulphuric acid, rarely resistant to $5 \%$ and never to $20 \%$.

The following tests gave totally negative results: casein digestion, with skimmed milk agar; tyrosine and xanthine digestion; tolerance of $10 \%$ sodium taurocholate; haemolysis of horse blood; indole production; citrate utilization. No pigment production or discoloration of the agar was observed on any medium.

\section{Cell-roall analyses}

Cell-wall hydrolysates for amino acid analyses were prepared as previously reported (Davis \& Baird-Parker, 1959b). Cell breakage with ballotini using a 'Microid' wrist-action shaker was also tested and yielded results comparable to those from organisms broken by the ultrasonic method.

Chromatography. Two-dimensional descending paper partition chromatography was used to analyse the amino acid constituents. The organic phase of the mixture$n$-butanol (4), glacial acetic acid (1), water (5)-was used as first solvent (16 hr.); 
and pyridine (50), ethanol (35), water (15), as the second (6 hr.). Runs were made upon Whatman no. 1 paper in lagged tanks. Papers were air dried and sprayed with $0 \cdot 25 \%(w / v)$ ninhydrin solution (in $95 \%$ acetone). The addition of a trace of collidine to this reagent was found helpful in that it causes certain amino acids to develop as distinctively coloured spots after heating $5 \mathrm{~min}$. at $105^{\circ}$.

The method of Hoare \& Work (1957) was used to distinguish the isomers of diaminopimelic acid.

Table 1. Cell-wall amino acid patterns determined in this study

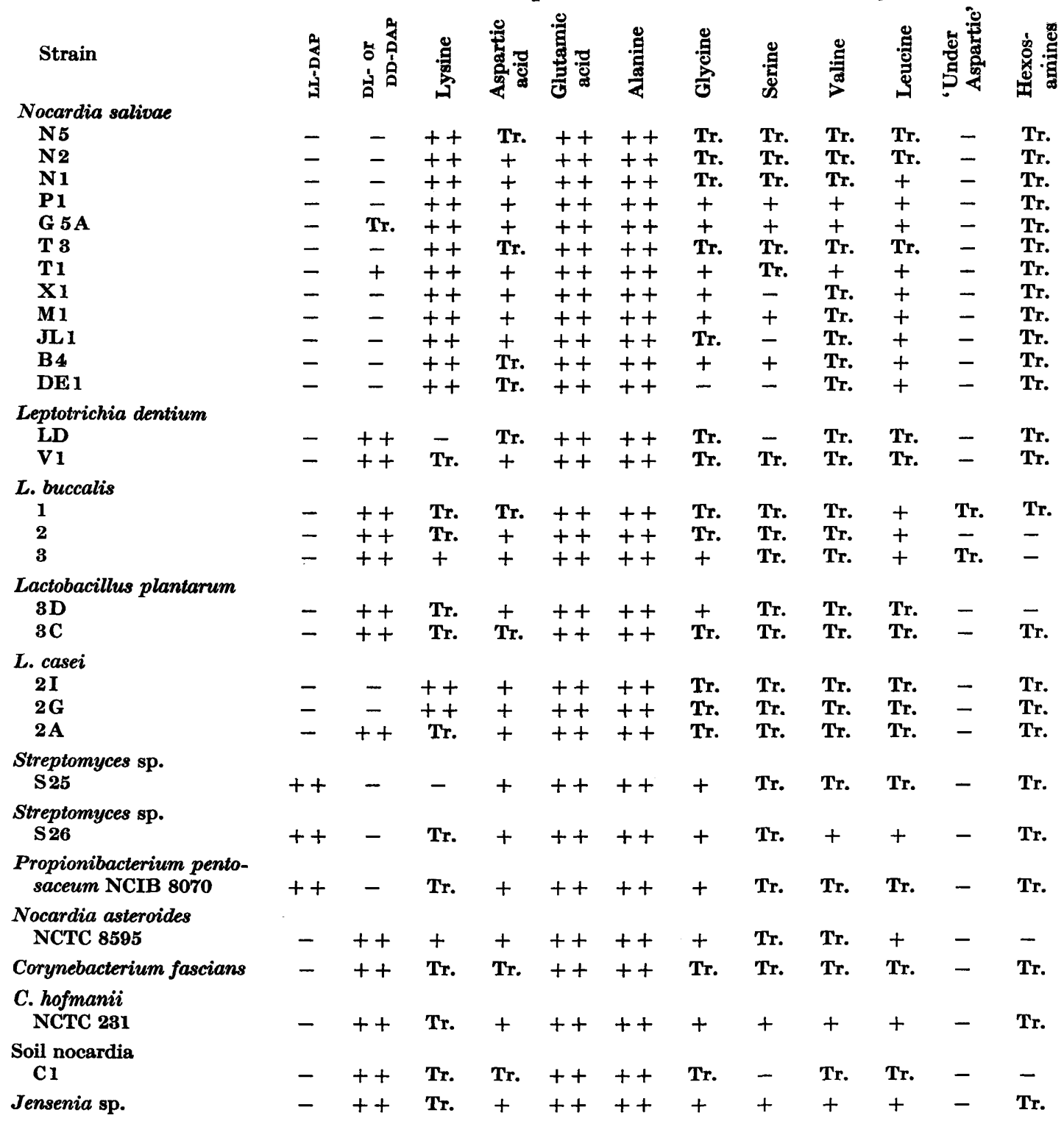


In addition to 12 strains of Nocardia salivae, 2 of Leptotrichia dentium, 3 of L. buccalis, 1 of Corynebacterium fascians, 1 of C. hofmannii (NCTC 231), 1 of Jensenia spp., 1 of Propionibacterium pentosaceum (NCIB 8070), 1 of Nocardia asteroides (NCTC 8595), 1 soil nocardia and 2 soil streptomyces (C 1, S 25, S 26 respectively, of Davis \& Baird-Parker, $1959 \mathrm{~b}$ ), and strains of Lactobacillus casei and L. plantarum, were examined for comparative purposes.

The results are shown in Table 1 ; in Table 2 the results for the oral aerobic actinomycetes are compared with certain relevant results from Cummins \& Harris $(1956,1958,1959 a, b)$, and are discussed later.

Three points arose from the cell-wall studies which do not bear directly upon the present problem but which require mention. First, the finding of an unidentified component ('under aspartic') in two of the three extracts of Leptotrichia buccalis, but not in those of $L$. dentium, suggests a possible taxonomic distinction. Secondly, we have examined nine strains of Lactobacillus case $i$ which were available in this laboratory and found three of them to possess DAP rather than lysine in the cell wall. In a previous publication (Davis \& Baird-Parker, 1959b) the predominance of DAP in a single strain of $L$. case $i$ was reported and when doubt was thrown upon the accuracy of this result it was checked, unfortunately, by the use of the other two strains which possess mainly DAP. We have not examined these strains of $L$. casei to determine the cause of these apparently aberrant results but now report that in our experience two out of three strains of $L$. casei yield results comparable with those reported by Cummins \& Harris (1956), and dissimilar to the results obtained from L. plantarum (see Table 1). Thirdly, the organisms named Jensenia (Bisset \& Moore, 1949) and Corynebacterium fascians (see Lacey, 1955) both exhibit cell-wall amino acid patterns of the Mycobacterium-Corynebacterium-Nocardia type.

\section{DISCUSSION}

The most significant feature of the results described above is the apparent taxonomic contradiction between the results of morphological, cultural and biochemical studies and those of the cell-wall analyses of Nocardia salivae. Upon the evidence of the former these oral bacteria are classifiable in the genus Nocardia. They possess the characteristic colonial and cellular features of the genus, are aerobic, catalase-positive and exhibit biochemical and cultural characters of the Nocardia type. Comparison with descriptions given in Bergey's Manual (1957), Topley and Wilson's Principles (1955), Waksman (1950), and similar texts, clearly indicates the genus Nocardia. The results of the cell-wall analyses do not, however, support this classification (see Davis \& Baird-Parker, 1959b) and appear to more closely resemble those obtained from the microaerophilic Actinomyces (see also Cummins \& Harris, 1959b).

Table 2 compares the cell-wall analysis results of Cummins \& Harris (1956, 1958, $1959 a, b)$ with those obtained in this laboratory with various organisms; from this and Table 1 the overall similarity between the results, particularly as regards major components, is readily seen. The quantitative evaluation of hydrolysate components upon essentially qualitative chromatograms is necessarily arbitrary and for this reason it is not possible to consider the occurrence of aspartic acid, glycine, serine, valine, leucine, etc., in our results and their absence, or omission, from the results of Cummins \& Harris, as highly significant. Consequently it seems more 


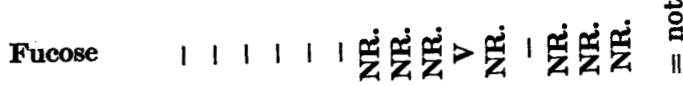

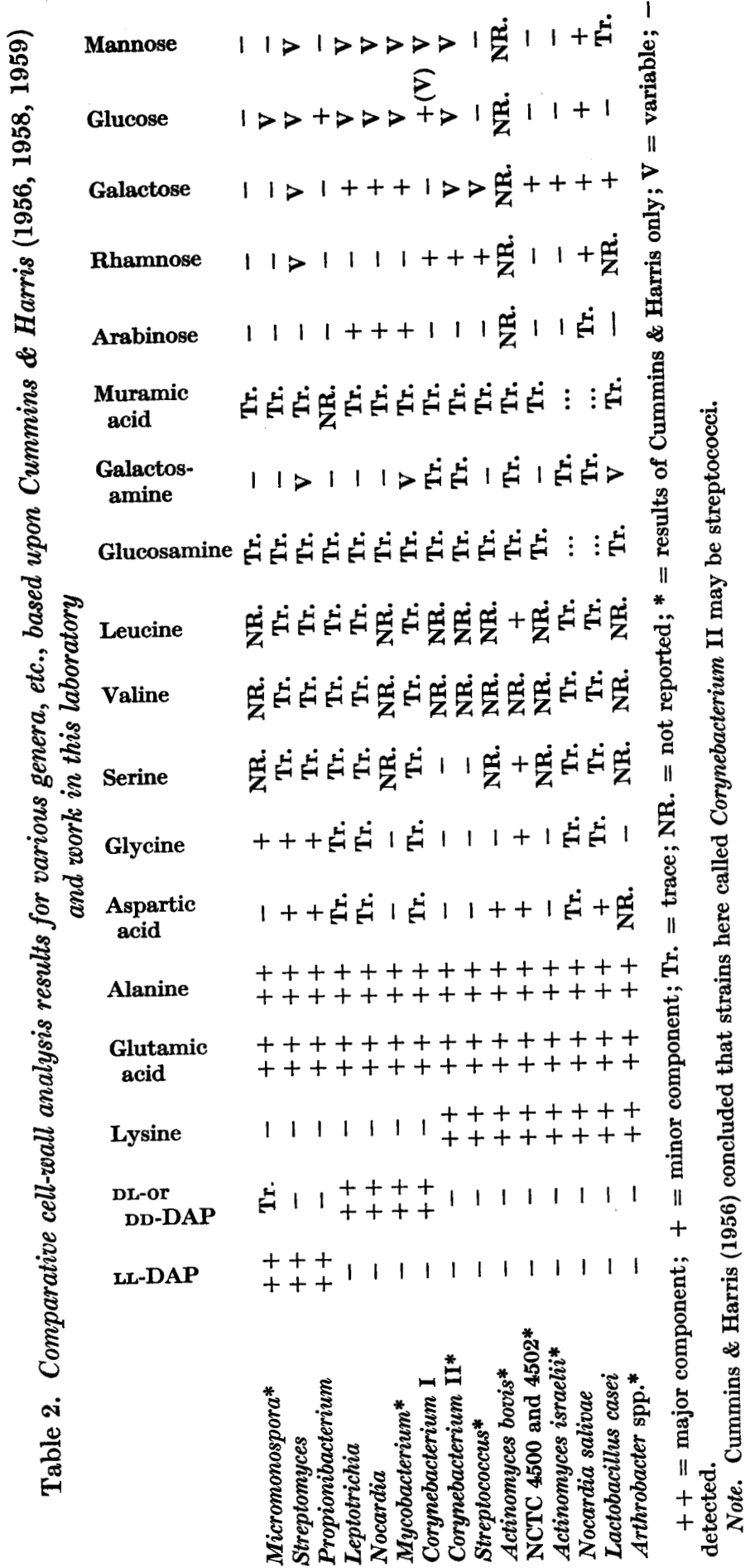


reasonable to compare our results for oral nocardia-like bacteria with the Actinomyces israelii results of Cummins \& Harris rather than those for $A$. bovis or the NCTC strains 4500 and 4502 in which Cummins \& Harris reported aspartic acid, glycine and serine, among others, as additional constituents. Apart from this point, the presence of galactose (see Davis \& Baird-Parker, $1959 b$ ) but nor hamnose or fucose in the present oral strains also suggests closer similarity to $A$. israelii.

Bearing in mind the comments made above about the morphological similarity between the organisms here described and Arthrobacter spp., it is of great interest that Cummins \& Harris (1959b) reported cell-wall analysis results for five out of seven named species of Arthrobacter as identical with those from Actinomyces israelii. This tempts us to suggest that Arthrobacter, Nocardia salivae, and Actinomyces may represent a related series of bacteria ranging from saprophytes to parasites. The genus Arthrobacter is already somewhat of a heterogeneous group of species held together by certain common morphological characters. Unfortunately the heterogeneity in cell-wall composition noted by Cummins \& Harris (1959b) does not correlate with that noticeable in other characters (Bergey's Manual, 1957). In view of certain dissimilarities, notably biochemical, between the organisms we have studied and the known characters of Arthrobacter species as defined at present, there seems little point in increasing the heterogeneity of Arthrobacter by classifying our organisms in this genus. We consider it unwise at this stage to transfer apparently anomalous species from one genus, e.g. Nocardia, to another, e.g. Arthrobacter, in which they may prove to be equally out of place when better understanding of this group of organisms is obtained. Upon the basis of amino acid patterns comparison is also possible with the results for Lactobacillus casei (Cummins \& Harris, 1958, noted the similarity between amino acid patterns from lactobacilli and Actinomyces bovis) and grossly similar patterns were reported by Cummins \& Harris (1956) in Streptococcus, Corynebacterium pyogenes and C. haemolyticum, which also contain rhamnose as a major cell-wall component (Corynebacterium II of Table 2). Although these comparisons appear to confound rather than facilitate diagnostic classification the possible phylogenetic implications are interesting.

It is well known that the anaerobic character of Actinomyces is variable. In many classifications (Ørskov, 1923; Erikson, 1935) aerobic and anaerobic strains, i.e. Nocardia and Actinomyces, have been grouped together. The recent work of Howell et al. (1959) indicated a series of types within the genus Actinomyces, ranging from the relatively aerobic to the anaerobic (Table 3 ). In the absence of sharp cultural differences between aerobic and anaerobic actinomycetes of the Nocardia-Actinomyces range, it is now common, and probably sound practice to consider catalasepositive strains as Nocardia and negative ones as Actinomyces. When the organisms of this study were first isolated we tentatively labelled them as Actinomyces naeslundii (Thompson \& Lovestedt, 1951) but now that this species has been more thoroughly described (Howell et al. 1959) various discrepancies are apparent and, in the absence of any satisfactory alternative, we allocate this oral actinomycete to the genus Nocardia. It is almost certain that this bacterium has been described before, but exact identification with any previous description has not been possible. Morris (1954) divided his oral nocardias (some of which were catalase-negative, according to his results) into eight types on the basis of fermentation reactions. Morris's type 7 appears fairly similar to the strains used in this study. The type $3 b$ 
of Onisi \& Nuckolls (1958) also resembled the present organisms. As in Morris's work, division into types was arbitrary and Onisi \& Nuckolls divided their type $3 b$ from $3 a$ on the basis of lactose fermentation even though this division placed some catalase-positive strains in type $3 a$ which these workers equated approximately with the genus Actinomyces (see Table 3 ).

The question of the taxonomic significance of catalase production in this group is an important one, and the general lack of information upon this subject renders comparison with many earlier reports of little value. It is, for example, very difficult to decide whether Thompson \& Lovestedt (1951), Naeslund (1925), Lord \& Trevett (1936), studied the organisms here described or the Actinomyces naeslundii of Howell et al. (1959).

Table 3. Comparison between Actinomyces israelii, A. naeslundii, and oral aerobic actinomycete (Nocardia salivae) upon basis of the characters reported by Howell et al. (1959)

\begin{tabular}{|c|c|c|c|c|c|c|c|}
\hline \multirow{2}{*}{$\begin{array}{l}\text { Characters used by } \\
\text { Howell et al. (1959) }\end{array}$} & \multicolumn{5}{|c|}{$\begin{array}{l}\text { Actinomyces israelii } \\
158 \text { strains -5 types }\end{array}$} & \multirow[b]{2}{*}{$\begin{array}{c}\text { Actinomyces } \\
\text { naeslundii } \\
42 \\
\text { strains }\end{array}$} & \multirow[b]{2}{*}{$\begin{array}{c}\text { Nocardia } \\
\text { salivae } \\
25 \\
\text { strains }\end{array}$} \\
\hline & $\begin{array}{c}1 \\
41 \\
\text { strains }\end{array}$ & $\begin{array}{c}2 \\
66 \\
\text { strains }\end{array}$ & $\begin{array}{c}3 \\
32 \\
\text { strains }\end{array}$ & $\begin{array}{c}4 \\
11 \\
\text { strains }\end{array}$ & $\begin{array}{c}5 \\
8 \\
\text { strains }\end{array}$ & & \\
\hline Catalase production & - & - & - & - & - & - & + \\
\hline Indole production & - & - & - & - & - & - & - \\
\hline Acetoin production & - & - & - & - & - & - & + \\
\hline Nitrate reduction & 50 & 50 & 42 & $\mathbf{3 6}$ & 49 & $\mathbf{8 8}$ & + \\
\hline $\begin{array}{l}10 \% \text { Bile tolerance } \\
\text { Fermentations ( } \% \\
\text { strains positive) }\end{array}$ & - & - & - & - & - & 60 & - \\
\hline Glucose & 100 & 100 & 100 & 80 & 90 & 90 & 100 \\
\hline Maltose & 100 & 100 & 90 & 70 & 70 & 80 & 100 \\
\hline Sucrose & 100 & 90 & 80 & 80 & 50 & 80 & 100 \\
\hline Raffinose & 100 & $\mathbf{0}$ & 30 & 40 & 10 & 80 & $\mathbf{0}$ \\
\hline Lactose & 100 & 100 & 90 & $\mathbf{0}$ & $\mathbf{0}$ & 60 & $\mathbf{0}$ \\
\hline Inositol & 75 & 40 & $\mathbf{5 0}$ & $\mathbf{5 0}$ & 10 & $\mathbf{5 0}$ & $\mathbf{0}$ \\
\hline Salicin & 10 & $\mathbf{0}$ & 20 & 40 & 10 & 10 & $\mathbf{0}$ \\
\hline Ribose & 75 & $\mathbf{V}$ & $\mathbf{V}$ & $\mathbf{V}$ & $\mathbf{V}$ & 10 & NT. \\
\hline Inulin & $\mathbf{0}$ & 50 & 40 & $\mathbf{0}$ & 20 & 10 & $\mathbf{0}$ \\
\hline Mannitol & 75 & 80 & $\mathbf{0}$ & $\mathbf{0}$ & 70 & $\mathbf{0}$ & $\mathbf{0}$ \\
\hline Xylose & 75 & 90 & 60 & 60 & $\mathbf{5 0}$ & $\mathbf{0}$ & $\mathbf{0}$ \\
\hline Arabinose & 10 & $\mathbf{0}$ & $\mathbf{0}$ & $\mathbf{0}$ & $\mathbf{0}$ & $\mathbf{0}$ & $\mathbf{0}$ \\
\hline Glycerol & $\mathbf{0}$ & $\mathbf{0}$ & $\mathbf{0}$ & $\mathbf{0}$ & $\mathbf{0}$ & $\mathbf{0}$ & 100 \\
\hline Melezitose & $\mathbf{0}$ & $\mathbf{0}$ & $\mathbf{0}$ & $\mathbf{0}$ & $\mathbf{0}$ & $\mathbf{0}$ & $\mathbf{0}$ \\
\hline Growth in air & - & - & - & - & - & \pm & + \\
\hline Growth in air $+\mathrm{CO}_{2}$ & \pm & - & - & - & - & $\overline{+}$ & + \\
\hline Growth in $\mathrm{N}_{2}+\mathrm{CO}_{2}$ & $\bar{t}$ & + & + & + & + & + & N'T. \\
\hline
\end{tabular}

All figures in table represent percentage of positive strains. NT. $=$ not tested; $+=$ positive; - = negative; $\pm=$ weak; $V=$ variable.

Note. Howell et al. acknowledge morphology as the primary diagnostic character in subdivision of Actinomyces.

The 'aerobic actinomyces' of Bibby \& Knighton (1941) were very similar to Nocardia salivae and these workers pointed out that the study of the aerobic oral actinomycetes had been, and probably still is, considerably hampered by the general tendency to use only anaerobic culture techniques for organisms which appear to resemble Actinomyces. 
Among other reports of aerobic actinomycetes isolated from man it is important to distinguish those which refer to Streptomyces or streptomyces-like nocardias, from those which refer to organisms of the type described in this paper. Erikson (1985) drew attention to the significance of 'powdery' colonies and its frequent lack of recognition by the workers who described them. The reports of Goadby (1903; 'Streptothrix buccalis'), Wright (1937), Franklin (1940) and Goldsworthy (1937) were of these streptomyces-like type of organisms. The Nocardia buccalis of Roger, Bory \& Sartory (Castellani \& Chalmers, 1919, p. 1061) also appears to be streptomyces-like but we have been unable to confirm this from the original description. Whether the so-called Actinomyces buccalis (NCTC 4523) represents this organism we do not know, but we have already reported on the streptomyces-like cell-wall nature of this organism (Davis \& Baird-Parker, $1959 b$ ).

A feature of Nocardia salivae strains is their saccharolytic power. This character sets them apart from the typical soil nocardias, and appears to be typical of Nocardia (Von Magnus, 1947) and Corynebacterium strains (Conn \& Dimmick, 1947; Laughton, 1950) which inhabit the mucous membranes of animals. It indicates that these strains represent ecological variants adapted to growth in these sites. Von Magnus (1947) suggested the name 'Lactomyces' for the acid-producing members of Ørskov's Group $2 \mathrm{~b}$, in order to indicate their intermediate taxonomic position between Lactobacillus and Actinomyces. We have already discussed this point, but upon the present evidence cannot come to any definite conclusion.

The general metabolic similarity between oral strains of Nocardia, Actinomyces (Pine \& Howell, 1956), and Leptotrichia (Davis \& Baird-Parker, 1959a) suggests that strong ecological pressures operate in the human mouth and that these members of the order Actinomycetales compete with, by simulating, the oral representatives of the Lactobacteriaceae, i.e. Lactobacillus and Streptococcus, for the available carbon sources. Preliminary attempts to determine the acid end-products of glucose metabolism by Nocardia salivae failed to detect lactic acid chromatographically, but this aspect will be pursued further.

Type strains of Nocardia salivae and Leptotrichia dentium have been sent to the National Collection of Type Cultures, Colindale Avenue, London, N.W.9, and allotted the numbers NCTC 10,207 (Nocardia salivae) and NCTC 10,206 (Leptotrichia dentium).

The authors wish to thank Dr A. C. Baird-Parker for his help in the early stages of this study.

\section{REFERENCES}

Baird-Parker, A. C. \& Davis, G. H. G. (1958). The morphology of Leptotrichia species. J. gen. Microbiol. 19, 446.

Bergey's Manual of Determinative Bacteriology (1957). 7th ed. Ed. R. S. Breed, E. G. D. Murray \& N. R. Smith. London: Baillière, Tindall and Cox.

BibBy, B. G. \& KNighton, H. T. (1941). The actinomyces of the human mouth. J. infect. Dis. 69, 148.

Bisset, K. A. (1955). The Cytology and Life-History of Bacteria, 2nd ed. Edinburgh: E. and S. Livingstone.

Bisset, K. A. (1957). Some observations upon the mode of sporulation and relationships of monosporous actinomycetes. J. gen. Microbiol. 17, 562.

Bisset, K. A. \& Davis, G. H. G. (1959). The oral actinomycetes. Arch. oral Biol. 1, 80. 
Casteluant, A. \& Chammers, A. J. (1919). Manual of Tropical Medicine, 3rd ed. London: Baillière, Tindall and Cox.

Chaplin, C. E. (1957). Life cycles in Arthrobacter pascens and A. terregens. Canad. J. Microbiol. 3, 103.

Conn, H. J. \& Drmmick, I. (1947). Soil bacteria similar in morphology to Mycobacterium and Corynebacterium. J. Bact. 54, 291.

Cummins, C. S. \& Harris, H. (1956). The chemical composition of the cell wall in some Gram-positive bacteria and its possible value as a taxonomic character. J. gen. Microbiol. 14, 583.

Cummins, C. S. \& Harnis, H. (1958). Studies on the cell-wall composition and taxonomy of Actinomycetales and related groups. J. gen. Microbiol. 18, 173.

Cummins, C. S. \& Harris, H. (1959a). Cell-wall composition in strains of Actinomyces isolated from human and bovine lesions. J. gen. Microbiol. 21, ii.

Cummrns, C. S. \& Harris, H. (1959b). Taxonomic position of Arthrobacter. Nature, Lond. 184, 831.

Davis, G. H. G. \& Baird-Parker, A. C. (1959a). Leptotrichia buccalis. Brit. dent. J. 106, 70.

Davis, G. H. G. \& Baird-Parker, A. C. (1959b). The classification of certain filamentous bacteria with respect to their chemical composition. J. gen. Microbiol. 21, 612.

DoDge, C. W. (1936). Medical Mycology. London: Henry Kimpton.

Dreschlen, C. (1919). Morphology of the genus Actinomyces I and II. Bot. Gaz. 69, 65, 147.

Dulaney, E. L. (1948). Observations on Streptomyces griseus. II. Nitrogen sources for growth and streptomycin production. J. Bact. 56, 305.

ErIKson, D. (1935). The pathogenic aerobic organisms of the Actinomyces group. Spec. Rep. Ser. med. Res. Coun., Lond. no. 203.

Frankin, G. C. H. (1940). Actinomycosis: a new species, pathogenic for man. Ann. intern. Med. 13, 1205.

GoADBY, K. W. (1903). The Mycology of the Mouth. London: Longmans.

Gondsworthy; N. E. (1937). Pulmonary actinomycosis caused by an acid-fast species of Actinomyces. J. Path. Bact. 45, 17.

Gray, P. H. H. \& Thornton, H. G. (1928). Soil bacteria that decompose certain aromatic compounds. Zbl. Bakt. (II. Abt.), 73, 74.

Hoare, D. S. \& Work, E. (1957). The stereoisomers of $\alpha-\epsilon$-diaminopimelic acid. II. Their distribution in the bacterial order Actinomycetales and in certain Eubacteriales. Biochem. J. 65, 441.

Howell, A., Murphy, W. C., Paul, F. \& Stephan, R. M. (1959). Oral strains of Actinomyces. J. Bact. 78, 82.

JENSEN, H. L. (1932). Contributions to our knowledge of the Actinomycetales. III. Further observations on the genus Micromonospora. Proc. Linn. Soc. N.S.W. 57, 173.

LACEY, M. S. (1955). The cytology and relationships of Corynebacterium fascians. Trans. Brit. mycol. Soc. 38, 49.

Laughton, N. (1950). Vaginal corynebacteria. J. Hyg., Camb. 48, 346.

Lord, F. T. \& Trevetr, L. D. (1936). The pathogenesis of Actinomycosis: recovery of actinomyces-like organisms from the normal mouth. J. infect. Dis. 58, 115.

von MAGnUS, R. (1947). Biochemical activities of actinomycetes of Group IIB (Ørskov) isolated from the human throat. Acta path. microbiol. scand. 24, 11.

Morris, E. O. (1951). The life-cycle of Actinomyces bovis. J. Hyg., Camb. 49, 46.

MorRIs, E. O. (1954). The bacteriology of the oral cavity. V. Corynebacteria and Grampositive filamentous organisms. Brit. dent. J. 97, 29.

NaEslund, C. (1925). Studies of Actinomyces from the oral cavity. Acta path. microbiol. scand. 2, 110.

Bisset, K. A. \& Moore, F. W. (1949). The relationship of certain branched bacterial genera. J. gen. Microbiol. 3, 387.

BuLleID, A. (1924). An experimental study of Leptothrix buccalis. Guy's Hosp. Rep. 74, 444. 
Naesuund, C. (1926). Studies of tartar formation. Acta path. microbiol. scand. 3, 637.

OnISI, M. \& Nuckolss, J. (1958). Descriptions of actinomycetes and other pleomorphic organisms recovered from pigmented carious lesions of the dentine of human teeth. Oral Surg. 11, 910.

Ørskov, J. (1923). Investigations into the Morphology of the Ray Fungi. Copenhagen: Levin and Munksgaard.

Pine, L. \& Howell, A. (1956). Comparison of physiological and biochemical characters of Actinomyces spp. with those of Lactobacillus bifidus. J. gen. Microbiol. 15, 428.

Rosebury, T. (1944). Parasitic actinomycetes and other filamentous micro-organisms of the mouth. Bact. Rev. 8, 189.

Smrth, N. R. (1946). Aerobic mesophilic sporeforming bacteria. Tech. Bull. U.S. Dep. Agric. no. 559.

Sundman, V. (1958). Morphological comparison of some Arthrobacter species. Canad. J. Microbiol. 4, 221.

Thompson, L. \& Lovestedt, S. A. (1951). An actinomyces-like organism obtained from the human mouth. Proc. Mayo Clin. 26, 169.

Topley and Wilson's Principles of Bacteriology and Immunity (1955). 4th ed. Ed. G. S. Wilson \& A. A. Miles. London: Edward Arnold.

Umarert, W. W. (1939). Studies on the proactinomyces. J. Bact. 38, 73.

Warsman, S. A. (1950). The Actinomycetes. Waltham, Mass.: Chronica Botanica.

Werb, R. B., Clark, J. B. \& Chance, H. L. (1954). A cytological study of Nocardia corallina and other actinomycetes. J. Bact. 67, 498.

Wright, H. A. (1937). A stable type of variant in certain aerobic actinomycetes. $Z \mathbf{Z b l}$. Babt. (I. Abt.), 138, 201. 


\section{EXPLANATION OF PLATES}

Puate 1

Figs: 1-6. Oral aerobic actinomycete (Nocardia salivae) stained by the phosphomolybdic acid and methyl green method for cell walls.

Fig. 1. Branching filamentous forms. $\times 2,500$.

Fig. 2. Triradiate and paired angle forms. $\times 1,250$.

Fig. 8. Segmenting and budding flaments. $\times 2,500$.

Fig. 4. Short swollen forms. $\times 1,250$.

Fig. 5. Filamentous form with terminal bifurcation. $\times 2,500$.

Fig. 6. Filament showing incipient budding. $\times 2,500$.

\section{Plate 2}

Figs. $7,10,11,13,14,15$. Colonies of Nocardia salivae on the surface of NAYS agar, showing various characteristic types. $\times c .40$.

Figs. 8, 9, 12. Filamentous cell forms in $N$. salivae, stained phosphomolybdic acid and methyl green for cell walls. The figures illustrate lateral branching (fig. 9 ), bifurcation (fig. 8), incipient bifurcation (figs. 9, 12), terminal (fig. 9), subterminal (fig. 12) and generalized (fig. 8) swelling of the flaments, and certain indeterminate cell inclusions (notably fig. 9). $\times 1,250$. 
Journal of General Microbiology, Vol. 23, No. 1

Plate 1
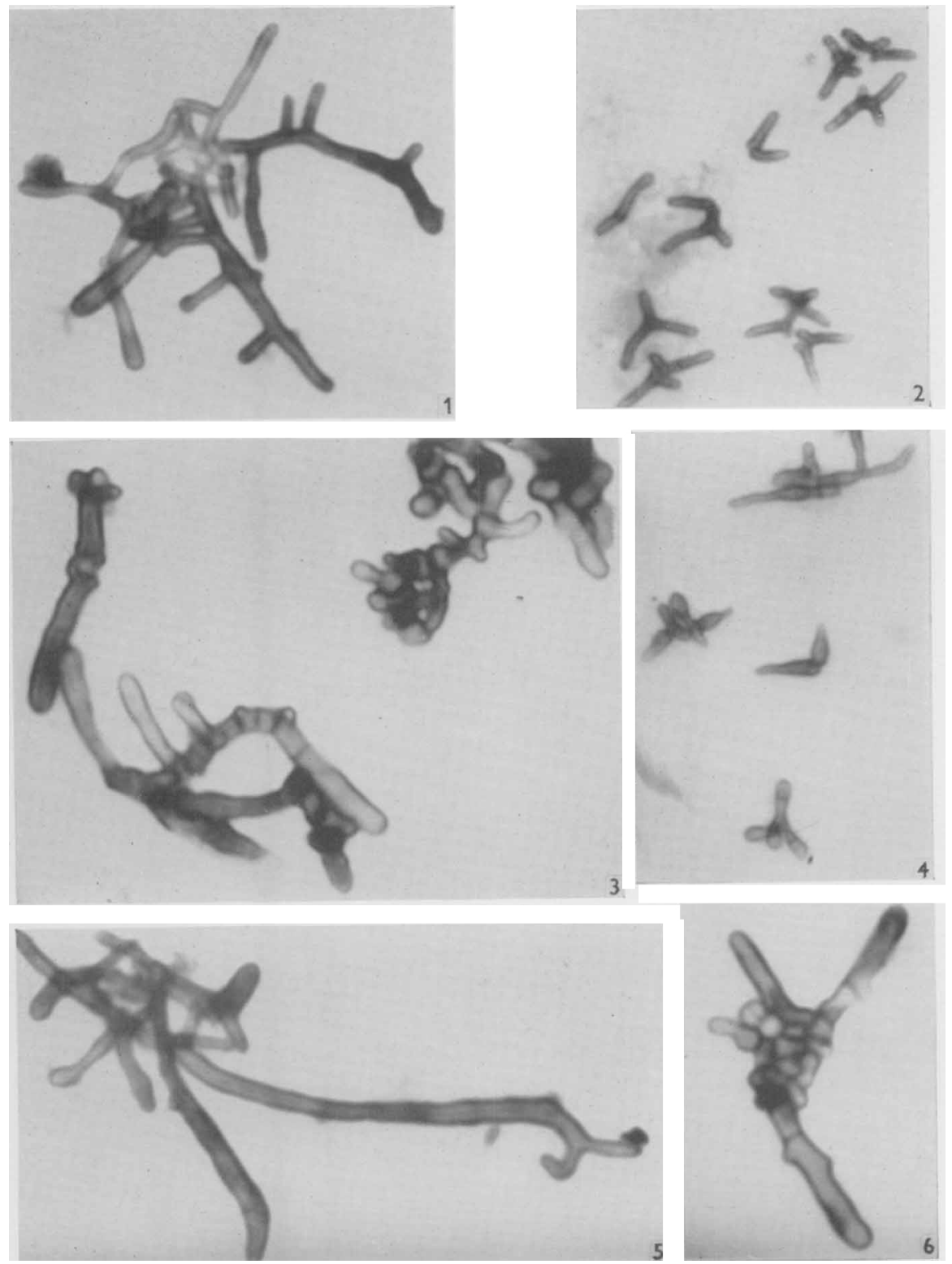

G. H. G. DAVIS and J. H. FREER 

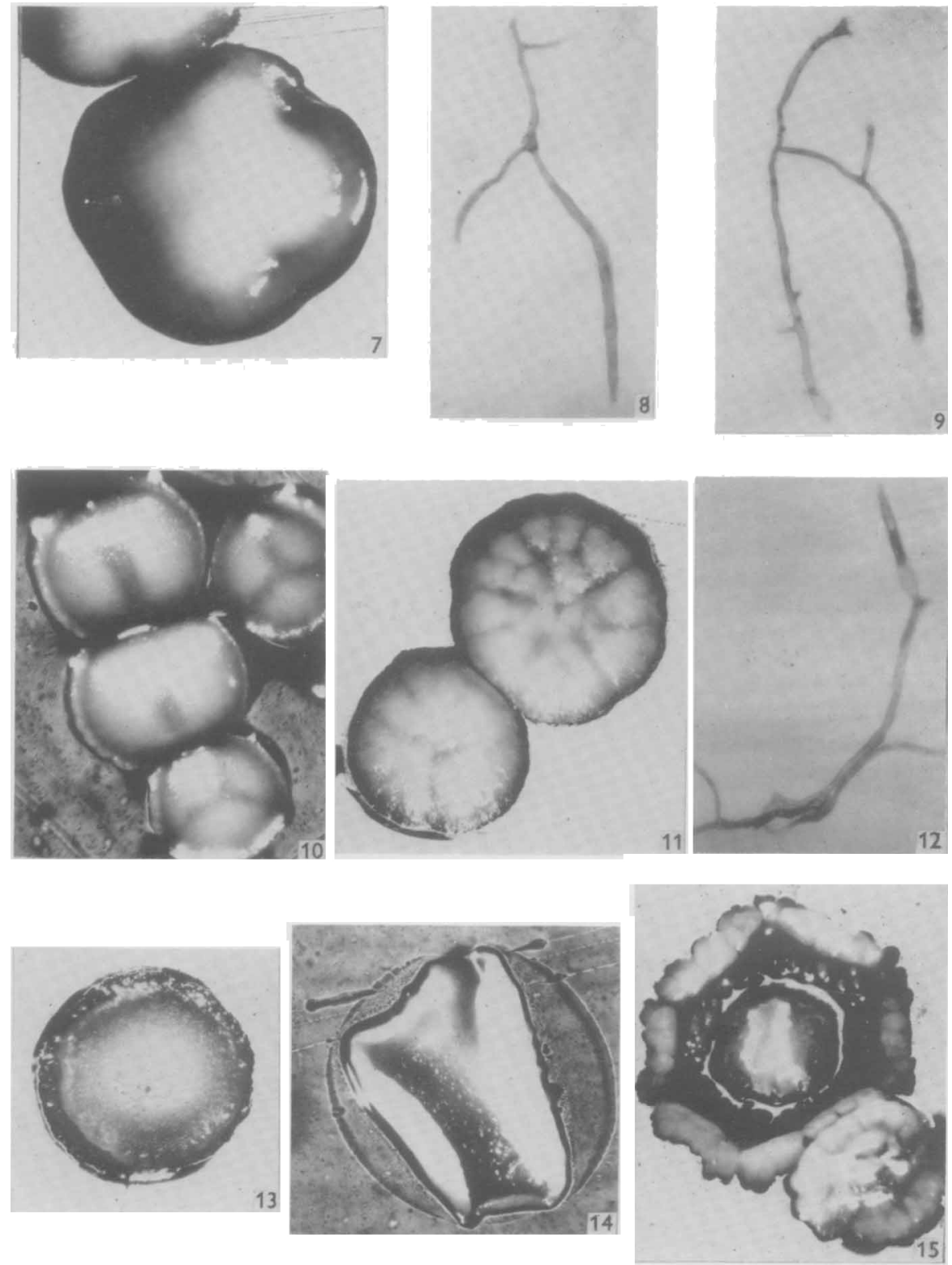

G. H. G. DAVIS AND J. H. FREER 